Check for updates

Cite this: RSC Adv., 2018, 8, 31972

Received 12th June 2018

Accepted 3rd August 2018

DOI: $10.1039 / c 8 r a 04497 j$

rsc.li/rsc-advances

\section{Influence of molecular weight on molecular dynamics and dynamic rheology of polypropylene glycol filled with silica}

\begin{abstract}
Furui Ma, Bei Xu, Yihu Song (DD * and Qiang Zheng
Molecular weight strongly influences the molecular dynamics and rheological responses of nanocomposites, which is far from being well understood. Herein molecular dynamics and rheological behaviors of hydrophilic fumed silica filled unentangled polypropylene glycol (PPG) were investigated as a function of weight averaged molecular weight $\left(M_{w}\right)$ of PPG and volume fraction $(\varnothing)$ of silica. It is shown that $M_{w}$ does not affect the glassy layers surrounding the nanoparticles and the segmental dynamics of the mobile PPG phase. On the other hand, the mobile PPG phase in the highly filled nanocomposites exhibits an abnormal "more fragile" to "stronger" transition with increasing $M_{w}$. The reinforcement and thinning behaviors are stronger in lower $-M_{w}$ nanocomposites with the "more fragile" mobile PPG phase. The results suggest that reinforcement of nanocomposites affects the dynamic fragility of the mobile phase of the matrix.
\end{abstract}

\section{Introduction}

Interactions between nanoparticles and polymers significantly influence the relaxation of polymers adjacent to particles, which is usually ascribed to the main cause influencing rheological and mechanical behaviors of nanocomposites..$^{1-4}$ The molecular weight, polarity and active groups of polymers strongly affect the interfacial interactions and relaxation behaviors. ${ }^{.511}$ Differences of molecular dynamics are macroscopically reflected in changes of glass transition temperature as well as thermal, mechanical electrical, light and other properties, ${ }^{12-19}$ which allows quantifying the interfacial interactions by means of differential scanning calorimetry (DSC), ${ }^{19}$ broadband dielectric spectrum (BDS) ${ }^{20-23}$ low field nuclear magnetic resonance, ${ }^{24-29}$ small angle neutron scattering, ${ }^{30,31}$ and so on. Both BDS and DSC methods are extensively applied to investigate interfacial interactions in nanocomposites. ${ }^{32,33}$ Besides the usual segmental dynamics ( $\alpha$ relaxation), an additional relaxation, namely, $\alpha^{\prime}$ relaxation, being two orders of magnitude slower than the $\alpha$ relaxation, could be detected in some nanocomposites containing restricted chains fractions, ${ }^{4,23,32,34}$ whose dielectric strength can be used to evaluate interfacial interactions $^{23}$ and estimate the fraction of restricted chains $\left(\varphi_{\mathrm{imm}}\right)^{22,35,36}$ By using temperature-modulated DSC, the fraction of glassy fractions with totally forbidden $\alpha$ relaxation might be detected according to $\varphi_{\mathrm{g}}=1-\Delta C_{\mathrm{p}} /\left[(1-w) \Delta C_{\mathrm{p}}^{0}\right] \cdot{ }^{37}$ Here, $w$ is weight fraction of filler, and $\Delta C_{\mathrm{p}}$ and $\Delta C_{\mathrm{p}}^{0}$ are heat capacity

MOE Key Laboratory of Macromolecular Synthesis and Functionalization, Department of Polymer Science and Engineering, Zhejiang University, Hangzhou 310027, China. E-mail: s_yho411@zju.edu.cn increments of the nanocomposites and neat polymer during glass transition, respectively.

Except for the significant influence of filler volume fraction $(\varnothing)$, the rheology of nanocomposites is highly dependent on weight-averaged molecular weight $\left(M_{\mathrm{w}}\right)$ of the matrix, ${ }^{38-40}$ nanocomposites with lower- $M_{\mathrm{w}}$ matrices exhibiting greater reinforcement and stronger nonlinearity. ${ }^{31,41,42}$ However, influences of $\varnothing$ and $M_{\mathrm{w}}$ on the interfacial interactions ${ }^{20,31,32,43}$ and rheological responses ${ }^{31,41,42}$ are far from being understood. Pissis, et al. ${ }^{36}$ using DSC and BDS find that, in silica and titania filled polydimethylsiloxane, $\varphi_{\text {imm }}$ does not change while $\varphi_{\mathrm{g}}$ increases with increasing $\varnothing .^{1,2}$ Klonos, et al. ${ }^{36,44}$ show that $\varphi_{\text {imm }}$ increases with specific surface area of filler and active sites of molecular chains. Zukoski, et al. ${ }^{31}$ using low field nuclear magnetic resonance method find that, in silica filled polyethyleneglycol nanocomposites, $\varphi_{\mathrm{g}}$ and $\varphi_{\mathrm{imm}}$ increase with increasing $\varnothing$ and $M_{\mathrm{w}}$. Considering that the interfacial interactions strongly influence rheology of nanocomposites, ${ }^{45-47}$ the present article is focused on the effects of $M_{\mathrm{W}}$ of unentangled, monodispersed polypropylene glycol (PPG) and $\varnothing$ of silica on the chains immobilization and rheology of the nanocomposites. Unentangled PPG, with $M_{\mathrm{w}}$ below critical entanglement molecular weight $5300 \mathrm{~g} \mathrm{~mol}^{-1}$ (ref. 48) or $7000 \mathrm{~g}$ $\mathrm{mol}^{-1,49}$ is a kind of oligomer widely used in traditional industrial fields such as coatings ${ }^{50,51}$ and adhesives ${ }^{52}$ as well as emerging materials like shear thickening fluid and liquid body armor. $^{53,54}$ Fumed silica is in practice used as rheological control agents to simultaneously modify the rheological, ${ }^{47,55,56}$ thermal and mechanical properties of $\mathrm{PPG}^{57-59}$ while the combined effects of $M_{\mathrm{w}}$ of PPG and $\varnothing$ of silica on the molecular dynamics have not been investigated thoroughly. Herein 
dynamics and rheological behaviors of hydrophilic fumed silica (A200) filled unentangled PPG matrices $\left(M_{\mathrm{w}}=425,1000,2000\right.$, 3000 , and $4000 \mathrm{~g} \mathrm{~mol}^{-1}$ ) are investigated thoroughly.

\section{Experimental section}

\section{Materials and sample preparation}

Hydroxyl-terminated polypropylene glycol (PPG) samples (dispersity index less than 1.02 , and weight-averaged molecular weight, $M_{\mathrm{w}}$, ranging from 425 to $4000 \mathrm{~g} \mathrm{~mol}^{-1}$ ) were supplied by Shandong Dongda Chem. Ind. Co., Zibo, China. Hydrophilic fumed silica (A200) of $12 \mathrm{~nm}$ in diameter of primary spherical particles (according to the provider) was provided by Evonik Degussa Co., Akron, OH, USA. A planetary mixer was used to mix A200 dehydrated at $110^{\circ} \mathrm{C}$ for at least $24 \mathrm{~h}$ with PPG. Mixing was performed at $300 \mathrm{rpm}$ for $60 \mathrm{~min}$ under vacuum to ensure a homogeneous dispersion quality. ${ }^{55}$ The resultant dispersions were extruded under pressure from the mixer to plastic cylinders $(300 \mathrm{~mL})$ and the cylinders were sealed and stored at room temperature.

\section{Characterization}

Rheological measurements were carried out on a stresscontrolled rheometer (AR-G2, TA Instruments, US) with a cone-and-plate geometry (diameter $60 \mathrm{~mm}$ and cone angle $1^{\circ}$, diameter $40 \mathrm{~mm}$ and cone angle $2^{\circ}$, or diameter $20 \mathrm{~mm}$ and cone angle $2^{\circ}$ depending on viscosity of the dispersions). A steady pre-shear at a shear rate of $0.1 \mathrm{~s}^{-1}$ for $180 \mathrm{~s}$ was applied to the samples to release extra normal force, following by a rest of $600 \mathrm{~s}$ before test. ${ }^{41,42}$ Dynamic frequency $(\omega)$-sweeps were performed at a strain amplitude $0.01 \%$ located in the linearity regime at $25{ }^{\circ} \mathrm{C}$.

Reversing heat capacities $C_{\mathrm{p}}$ of the nanocomposites during glass transition of PPG were detected by a differential scanning calorimeter (Q100, TA Instruments, US) under modulated mode. Samples (10-12 mg) cooled to $-90{ }^{\circ} \mathrm{C}$ were tested at a heating rate of $1^{\circ} \mathrm{C} \mathrm{min}^{-1}$ with a superimposed temperature modulation of $\pm 1{ }^{\circ} \mathrm{C}$ in amplitude and $120 \mathrm{~s}$ in period. ${ }^{56} \mathrm{~A}$ sapphire sample was used to calibrate the signal of capacity before measurement. Glass transition temperature $\left(T_{\mathrm{g}}\right)$ and the associated heat capacity increments $\left(\Delta C_{\mathrm{p}}\right)$ of the nanocomposites were quantified using the software package "Universal Analysis 2000" provided by TA Instruments.

Broadband dielectric spectra (BDS) were measured by a high resolution broadband dielectric spectrometer (Novocontrol GmbH Concept 40, Novocontrol Techn. Co., Germany). The samples were settled in between the two electrode plates and three Teflon spacers were used to control the thickness. The sample leaked out was removed and the electrode plates were placed in an anti-leaking cell. The measurements were carried out in the frequency range from $10^{-1} \mathrm{~Hz}$ to $10^{7} \mathrm{~Hz}$. Complex permittivity, $\varepsilon^{*}(\omega)$, at angle frequency $\omega$ can be fitted by Havriliak-Negami (HN) equation ${ }^{60}$

$$
\varepsilon^{*}(\omega)=\varepsilon_{\infty}+\sum_{j} \frac{\Delta \varepsilon_{j}}{\left[1+\left(i \omega \tau_{\mathrm{HN}, j}\right)^{\alpha_{j}}\right]^{\beta_{j}}}+i \frac{\sigma}{\varepsilon_{0} \omega^{s}}
$$

to determine characteristic relaxation time $\tau_{\mathrm{HN}}$. Here $\alpha_{j}\left(0 \leq \alpha_{j}\right.$ $\leq 1)$ and $\beta_{j}\left(0 \leq \beta_{j} \leq 1\right)$ are shape factors, indicative of the breadth and asymmetry of a relaxation $j$, respectively. $\Delta \varepsilon=\varepsilon_{0}-$ $\varepsilon_{\infty}$ is dielectric strength, and $\varepsilon_{0}$ and $\varepsilon_{\infty}$ are dielectric constants at limiting high and low angle frequencies that are determined by data fitting, respectively. The third term in eqn (1) represents the contribution of DC conduction and $\sigma$ is conductivity and $s(0$ $<s \leq 1$ ) is a fitting parameter responsible for the slope of the conductivity $(s=1$ for ohmic conductivity, and $1<s<1$ if there is an influence of electrode polarization). ${ }^{61}$ The characteristic relaxation time $\tau_{\mathrm{HN}}$ is related to the time of maximum $\operatorname{loss}\left(\tau_{\max }\right)$ by

$$
\tau_{\max }=\tau_{\mathrm{HN}}\left(\sin \frac{\alpha \beta}{\beta+1} \frac{\pi}{2}\right)^{\frac{1}{\alpha}}\left(\sin \frac{\alpha}{\beta+1} \frac{\pi}{2}\right)^{-\frac{1}{\alpha}}
$$

\section{Results and discussion}

To reveal the influence of silica on the glass transition of the PPG fraction in the nanocomposites, heat capacity of the nanocomposites $\left(C_{\mathrm{p}}\right)$ is normalized by weight fraction of PPG (1 $-w$ ). Fig. 1 shows normalized specific reversing heat capacity, $C_{\mathrm{p}} /(1-w),{ }^{42}$ as a function of temperature $(T)$ for the nanocomposites with various $\varnothing$ and $M_{\mathrm{w}}$ and the inset shows $T_{\mathrm{g}}$ as a function of $\varnothing$. While $T_{\mathrm{g}}$ increases with $M_{\mathrm{w}}$, it is nearly independent of $\varnothing$. It means that the nanoparticles do not necessarily affect the glass transition of the free PPG phase associated with a much small characteristic length scale typically covering only 3-5 monomers. ${ }^{62}$ Furthermore, the deviation of $T_{\mathrm{g}}\left(\Delta T_{\mathrm{g}} \approx\right.$ 0 ) is not affected by $M_{\mathrm{w}} \cdot{ }^{63}$ On the other hand, $C_{\mathrm{p}}^{0}$ decreases with $M_{\mathrm{w}}$ and the increment of $C_{\mathrm{p}} /(1-w)$ during the glass transition, $\Delta C_{\mathrm{p}} /(1-w)$, decreases with $\varnothing$, proving that a fraction of PPG immobilized by silica does not undergo glass transition and forms glassy layers surrounding the nanoparticles. On the contrary, the chains beyond the glassy layer are as mobile as those in pure $\mathrm{PPG}^{\mathbf{6 4}}$ indicating that the confinement effects are thus mostly dominated by interfacial phenomena. ${ }^{62}$

In the silica filled PPG nanocomposites, the interfacial hydrogen bonding interaction facilitates the immobilization of PPG chains, which strongly reduces the chains mobility and forbids their segmental dynamics. ${ }^{47,55,56}$ Microscopic structures of dispersions may be described by a three-phase model that

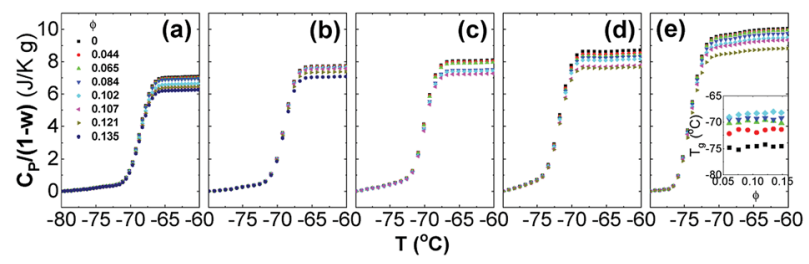

Fig. $1 C_{p} /(1-w)$ as a function $T$ for silica filled PPG with $M_{w}=4000$ (a), 3000 (b), 2000 (c), 1000 (d) and $425 \mathrm{~g} \mathrm{~mol}^{-1}$ (e). The silica volume fraction $(\varnothing)$ is indicated in (a). Inset in (e) shows $T_{\mathrm{g}}$ as a function of $\varnothing$ for the nanocomposites with PPG of $M_{w}=4000$ (diamond), 3000 (downtriangle), 2000 (up-triangle), 1000 (circle), and $425 \mathrm{~g} \mathrm{~mol}^{-1}$ (square). 

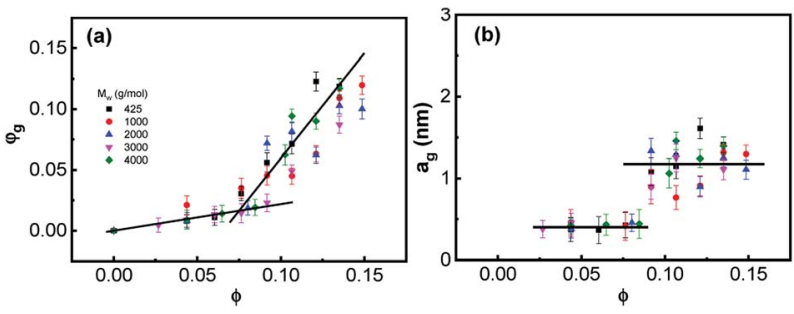

Fig. 2 (a) Fraction of glassy layer $\varphi_{\mathrm{g}}$ and (b) its thicknesses $a_{\mathrm{g}}$ as a function of $\varnothing$. The lines are for guide of the eyes.

assumes that, beside the free phase, the polymer forms an inner glassy layer surrounding the hard nanoparticles. ${ }^{\mathbf{4 , 2 3 , 3 2 , 6 5 , 6 6}}$ Assuming that density of PPG in the nanocomposites is constant everywhere, the fraction of the glassy layers $\left(\varphi_{\mathrm{g}}\right)$ is estimated according to $\varphi_{\mathrm{g}}=1-\Delta C_{\mathrm{p}} /\left[(1-w) \Delta C_{\mathrm{p}}^{0}\right],{ }^{37}$ from which the geometrical thickness of the glassy layers $\left(a_{\mathrm{g}}\right)$ surrounding geometric ideal spheres of diameter $r(6.8 \mathrm{~nm})$ is determined by $a_{\mathrm{g}} / r=\left[\varphi_{\mathrm{g}}(1-\varnothing) / \varnothing+1\right]^{1 / 3}-1 .^{55,56}$ Fig. 2 shows $\varphi_{\mathrm{g}}$ and $a_{\mathrm{g}}$ as a function of $\varnothing . \varphi_{\mathrm{g}}$ increases linearly against $\varnothing$ and the increment becomes faster at $\varnothing>0.085$. Concomitantly, $a_{\mathrm{g}}$ keeps constant at about $0.4 \mathrm{~nm}$ and $1.2 \mathrm{~nm}$ at $\varnothing<0.085$ and $\varnothing>0.085$, respectively, which corresponds to about 5 and 15 monomer units being independent of $M_{\mathrm{w}} \cdot{ }^{20,31,32}$ The formed glassy layers are important for providing volume repulsive force for dispersing the nanoparticles stably. ${ }^{\mathbf{9 , 1 0 , 6 7}}$

To reveal the influence of silica on the glass transition of the PPG fraction in the nanocomposites, dielectric loss of the nanocomposites $\left(\varepsilon^{\prime \prime}\right)$ is normalized by volume fraction of PPG (1 - $)$. Fig. 3 shows normalized dielectric loss $\varepsilon^{\prime \prime} /(1-\varnothing)$ as a function of frequency $f=\omega / 2 \pi$ of the nanocomposites at $-40{ }^{\circ} \mathrm{C}$. Except for the DC conduction process in the low- $f$ region, a strong $\varepsilon^{\prime \prime}$ peak in the high- $f$ region is related to $\alpha$ relaxation; ${ }^{32,60,68,69}$ another relaxation related to normal mode of molecular chains appears in the medium $f$ region for $M_{\mathrm{w}} \geq$ $1000 \mathrm{~g} \mathrm{~mol}^{-1}$. The introduction of silica slight alters symmetry of the $\alpha$ relaxation, suggesting that there is possible a small fraction of chains at the interface with dynamics differing from the mobile phase. The HN function is used for distinguishing different relaxations by using the WinFIT Curve Fitting Software developed by NOVOCONTROL. However, due to the

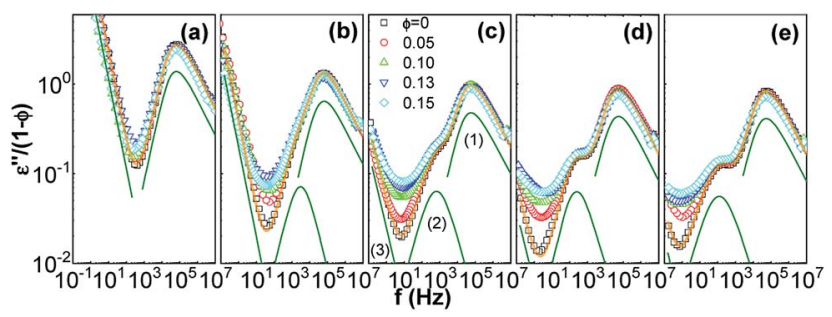

Fig. $3 \varepsilon^{\prime \prime} /(1-\varnothing)$ as a function of $f$ for silica filled PPG of $M_{w}=425(a)$, 1000 (b), 2000 (c), 3000 (d), and $4000 \mathrm{~g} \mathrm{~mol}^{-1}$ (e) at $-40{ }^{\circ} \mathrm{C}$. The dielectric spectra of PPG are fitted by $\mathrm{HN}$ equation (thick curves) composed by $\alpha$ relaxation (1), normal mode (2) and DC conduction processes (3). The distinguished individual processes are expressed as thin curves which are shifted downwards by a factor of 2 .
Table $1 \mathrm{HN}$ parameters for the dispersions

\begin{tabular}{|c|c|c|c|c|c|c|c|}
\hline \multirow[b]{2}{*}{$\begin{array}{l}M_{\mathrm{w}} \\
\left(\mathrm{g} \mathrm{mol}^{-1}\right)\end{array}$} & \multirow[b]{2}{*}{$\varnothing$} & \multicolumn{3}{|c|}{ Normal mode } & \multicolumn{3}{|c|}{$\alpha$ relaxation } \\
\hline & & $\begin{array}{l}\varepsilon_{\mathrm{NM}} / \\
(1-\varnothing)\end{array}$ & $\alpha_{j}$ & $\beta_{j}$ & $\begin{array}{l}\varepsilon_{\alpha} l \\
(1-\varnothing)\end{array}$ & $\alpha_{j}$ & $\beta_{j}$ \\
\hline \multirow[t]{3}{*}{425} & 0 & - & - & - & 9.37 & 0.93 & 0.44 \\
\hline & 0.11 & - & - & - & 9.07 & 0.88 & 0.48 \\
\hline & 0.15 & - & - & - & 8.42 & 0.87 & 0.49 \\
\hline \multirow[t]{3}{*}{1000} & 0 & 0.18 & 1.00 & 1.00 & 4.44 & 1.00 & 0.53 \\
\hline & 0.11 & 0.23 & 1.00 & 1.00 & 4.23 & 1.00 & 0.52 \\
\hline & 0.15 & 0.22 & 1.00 & 1.00 & 4.15 & 1.00 & 0.51 \\
\hline \multirow[t]{3}{*}{2000} & 0 & 0.28 & 1.00 & 1.00 & 3.48 & 1.00 & 0.49 \\
\hline & 0.11 & 0.33 & 0.94 & 0.99 & 3.50 & 1.00 & 0.48 \\
\hline & 0.15 & 0.32 & 0.97 & 1.00 & 3.21 & 1.00 & 0.48 \\
\hline \multirow[t]{3}{*}{3000} & 0 & 0.32 & 1.00 & 1.00 & 3.19 & 1.00 & 0.45 \\
\hline & 0.11 & 0.31 & 0.99 & 0.97 & 2.95 & 1.00 & 0.44 \\
\hline & 0.15 & 0.33 & 0.96 & 0.96 & 2.83 & 1.00 & 0.44 \\
\hline \multirow[t]{3}{*}{4000} & 0 & 0.28 & 1.00 & 1.00 & 2.97 & 1.00 & 0.48 \\
\hline & 0.11 & 0.30 & 0.86 & 0.99 & 2.82 & 1.00 & 0.44 \\
\hline & 0.15 & 0.30 & 0.88 & 0.69 & 2.70 & 1.00 & 0.42 \\
\hline
\end{tabular}

interference of the normal mode, it is hard to distinguish a fraction of dynamically retarded interfacial phase. Thus the fitting is performed using one $\mathrm{HN}$ function describing the segmental dynamics of the mobile polymer. The HN parameters are listed in Table 1 . The nanocomposites of $M_{\mathrm{w}}=1000,2000$ and $3000 \mathrm{~g} \mathrm{~mol}^{-1}$ have different shape factors $\alpha_{j}$ and $\beta_{j}$ at different $\varnothing$, revealing the possibility of the dynamics modification in the close vicinity of silica nanoparticles. Especially, the presence of silica slightly influences the shape factors of the normal mode and $\alpha$ relaxation of the nanocomposites with $M_{\mathrm{w}}$ $=4000 \mathrm{~g} \mathrm{~mol}^{-1}$ and the $\alpha$ relaxation of those with $M_{\mathrm{w}}=425 \mathrm{~g}$ $\mathrm{mol}^{-1}$. Nevertheless, the position and normalized dielectric strength of the $\alpha$ relaxation are independent of $\varnothing$, suggesting that the presence of silica does not significantly influence the segmental dynamics of the mobile PPG phase. ${ }^{68}$

The maximum relaxation times $\left(\tau_{\max }\right)$ of the $\alpha$ relaxation and normal mode are determined, as plotted in Fig. 4a as a function of $1 / T$ for pure PPG. It is found that $\tau_{\max }$ of these two relaxations obeys Vogel-Fulcher-Tammann (VFT) equation

$$
\tau_{\max } \sim \exp \left(\frac{D T_{0}}{T-T_{0}}\right)
$$
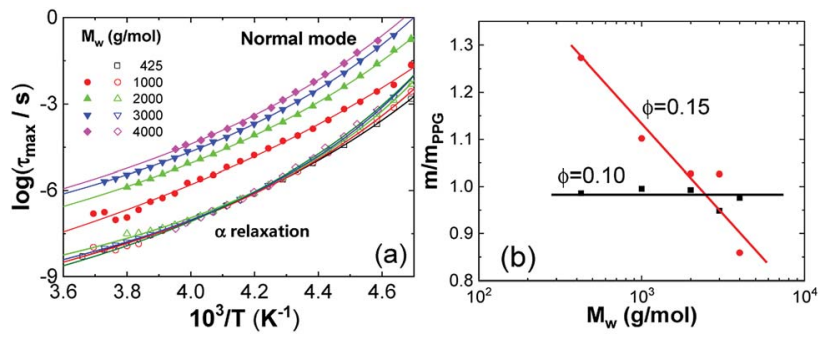

Fig. 4 (a) VFT fits to normal mode (solid symbols) and $\alpha$ relaxation (hollow symbols) of PPG of different $M_{\mathrm{w}}$ and (b) relative fragility $\mathrm{m} /$ $m_{P P G}$ as a function of $M_{w}$ at $\varnothing=0.10$ and 0.15 . 
Table 2 VFT parameters for the dispersions

\begin{tabular}{|c|c|c|c|c|c|c|c|}
\hline \multicolumn{2}{|c|}{ Nanocomposites } & \multicolumn{4}{|c|}{$\alpha$ relaxation } & \multicolumn{2}{|c|}{ Normal mode } \\
\hline$M_{\mathrm{w}}$ & $\varnothing$ & $T_{\mathrm{g}(\mathrm{BDS})}(\mathrm{K})$ & $T_{0}(\mathrm{~K})$ & $D$ & $m$ & $T_{0}(\mathrm{~K})$ & $D$ \\
\hline & 0.10 & 196.2 & 160.4 & 7.8 & 83.2 & - & - \\
\hline & 0.15 & 195.7 & 163.9 & 7.8 & 107.4 & - & - \\
\hline 1000 & 0 & 198.3 & 164.9 & 7.1 & 90.4 & 162.8 & 6.8 \\
\hline \multirow[t]{3}{*}{2000} & 0 & 200.3 & 167.3 & 6.9 & 92.2 & 162.7 & 7.7 \\
\hline & 0.10 & 200.2 & 167.1 & 6.9 & 91.5 & 161.8 & 7.3 \\
\hline & 0.15 & 200.5 & 168.3 & 6.7 & 94.7 & 161.9 & 7.4 \\
\hline \multirow[t]{3}{*}{3000} & 0 & 200.6 & 168.7 & 6.6 & 95.3 & 161.3 & 7.9 \\
\hline & 0.10 & 200.3 & 167.9 & 6.5 & 90.4 & 161.9 & 8.0 \\
\hline & 0.15 & 200.4 & 168.9 & 6.6 & 97.8 & 160.7 & 8.3 \\
\hline
\end{tabular}

where $T_{0}$ is Vogel temperature, $\tau_{0}$ is a characteristic time associated with vibration lifetimes, and $D$ is fragility parameter. ${ }^{70}$ $T_{\mathrm{g} \text { (BDS) }}$ of PPG and it nanocomposites is estimated as the temperature at $\tau_{\max }=10^{2} \mathrm{~s}$ for the $\alpha$ relaxation (as shown in Table 2), ${ }^{71,72}$ which is about $3-4{ }^{\circ} \mathrm{C}$ lower than that determined by DSC at $1{ }^{\circ} \mathrm{C} \min ^{-1}$. The dynamic fragility $(m)$, referring to deviations from Arrhenius $T$-dependence of $\alpha$ relaxation $^{73,74}$ is determined according to ${ }^{75}$

$$
m=\frac{\frac{D T_{0}}{T_{\mathrm{g}}}}{\ln (10)\left(1-\frac{T_{0}}{T_{\mathrm{g}}}\right)^{2}}
$$

The parameter $m$ governing breadth of glass formation is related to chain packing ability and interactions. ${ }^{76,77}$ The values of $m$ are listed in Table 2, the variation of the pure polymers with $M_{\mathrm{w}}$ being in consistence with previous observations. ${ }^{78}$ Filling at $\varnothing=0.10$ does not alter $m$ and $T_{\mathrm{g}}$ (Table 2 and Fig. $4 \mathrm{~b}$ ), suggesting that the formed glassy layers totally shield the interactions between silica nanoparticles and the free PPG phase. At $\varnothing$ $=0.15$, however, relative fragility $\left(\mathrm{m} / \mathrm{m}_{\mathrm{PPG}}\right)$ decreases linearly with $M_{\mathrm{W}}$ in a semi-logarithmic plot (Fig. 4b), which tends to indicate a filling induced "more fragile" to "stronger" transition without interfering the glass transition. The behaviour at $\varnothing=$ 0.15 is different from the general trend that $m$ and $T_{\mathrm{g}}$ vary proportionally in a variety of glass forming polymers and hydrogen bonding organic liquids, ${ }^{71}$ as well as some nanocomposites like C60 filled polystyrene. ${ }^{79}$ Many experiments ${ }^{80,81}$ and simulation investigations ${ }^{73,82}$ report an increase or decrease in $m$ when attractive or repulsive nanoparticles are uniformly distributed in the polymer matrix. A filling induced fragile to strong transition under nanoconfinement ${ }^{83}$ in the absence of strong interfacial interactions, accompanying with reduction or nonvariation of $T_{\mathrm{g}}{ }^{84-86}$ has been generally rationalized as emerging from a finite-size truncation of the cooperative rearrangements that are posited to drive fragile (non-Arrhenius) relaxation dynamics. ${ }^{87-90}$ However, the role of fragility in nanoconfinement effects remains poorly understood in general. Nonproportional variations of $m$ and $T_{\mathrm{g}}$ are frequently met, for examples, in ultrathin polymer films where interfacial effects dominate, ${ }^{\mathbf{9 1}, 92}$ or in nanocomposites with either plasticizing or antiplasticizing fillers. ${ }^{93}$ In the silica filled PPG nanocomposites at $\varnothing=0.15$, the breakdown of $m$ and $T_{\mathrm{g}}$ proportionality for $M_{\mathrm{w}}=$ $4000 \mathrm{~g} \mathrm{~mol}^{-1}$ is similar to the behaviour of ultrathin polymer films and might be ascribed to the release of packing frustration. On the other hand, the abnormal $m$ and $T_{\mathrm{g}}$ proportionality in the low- $M_{\mathrm{w}}$ nanocomposites might be related to elimination of chain ends by nanoparticles and their glassy layers. Unlike some other nanocomposites, for example, silica filled polyvinyl acetate $^{4}$ and poly(2-vinylpyridine), ${ }^{32,65}$ the $\alpha^{\prime}$ relaxation assigned to restrained segmental dynamics of chains absorbed on the nanoparticles does not seem to be significant.

Fig. 5 shows influences of $\varnothing$ and $M_{\mathrm{w}}$ on storage and loss moduli $\left(G^{\prime}\right.$ and $\left.G^{\prime \prime}\right)$ as a function of $\omega$ for the nanocomposites in the linear viscoelastic region. Unentangled PPG exhibits linear rheological response characterized by the classic terminal flow law $\left(G^{\prime} \sim \omega^{2}, G^{\prime \prime} \sim \omega^{1}\right)^{94}$ in the $\omega$ range achieved. As $\varphi$ and $M_{\mathrm{w}}$ increase, both $G^{\prime}$ and $G^{\prime \prime}$ increase and their $\omega$-dependences become gradually lessened, implying the formation of stressbearing filler backbones connected by adsorbed chains. All the nanocomposites at $\varnothing \leq 0.15$ are sol-like $\left(G^{\prime}<G^{\prime \prime}\right)$ except for that of $M_{\mathrm{w}}=425 \mathrm{~g} \mathrm{~mol}^{-1}$ and $\varnothing=0.15$ that behaves gel-like $\left(G^{\prime}\right.$ $\left.>G^{\prime \prime}\right)$. The highly filled PPG of higher- $M_{\mathrm{w}}$, for example, the nanocomposite of $\varnothing=0.16$ and $M_{\mathrm{w}}=3000 \mathrm{~g} \mathrm{~mol}^{-1}$, would also behave gel-like.

Fig. 6 shows influences of $\varnothing$ and $M_{\mathrm{w}}$ on $\omega$-dependence of relative complex viscosity $\left(\left|\eta_{\mathrm{r}}^{*}\right|\right)$ defined as ratio of complex viscosity of the nanocomposites over the Newtonian viscosity of unentangled PPG. While $\left|\eta_{\mathrm{r}}^{*}\right|$ increases with $\varnothing$, it decreases markedly with increasing $M_{\mathrm{w}}$. Furthermore, the gel-like nanocomposite with $\varnothing=0.15$ and $M_{\mathrm{w}}=425 \mathrm{~g} \mathrm{~mol}^{-1}$ demonstrates a shear-thinning behaviour being much more significant than that of the sol-like nanocomposites. It is suggested that 


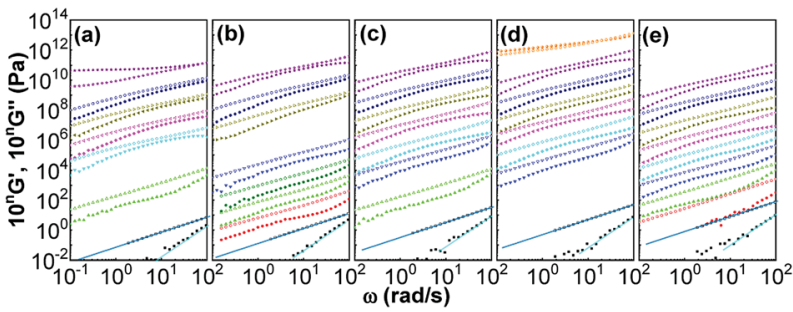

Fig. $5 \omega$-dependence of $G^{\prime}$ (solid symbols) and $G^{\prime \prime}$ (hollow symbols) for silica filled PPG of $M_{w}=425$ (a), 1000 (b), 2000 (c), 3000 (d), and $4000 \mathrm{~g} \mathrm{~mol}^{-1}$ (e). The data are shifted by a factor of $10^{n}$ for $\varnothing=0(n=$ 0 , squares), 0.03 ( $n=1$, circles), 0.04 ( $n=2$, up-triangles), 0.06 ( $n=3$, pentagons), 0.08 ( $n=4$, down-triangles), 0.09 ( $n=5$, diamonds), 0.11 ( $n=6$, left-triangles), 0.12 ( $n=7$, right-triangles), 0.14 ( $n=8$, hexagons), 0.15 ( $n=9$, stars), and 0.16 ( $n=10$, spheres). The straight lines are drawn according to classic terminal flow law.

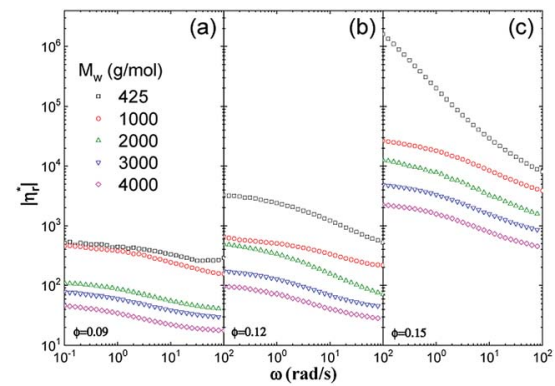

Fig. $6 \omega$-dependence of $\left|\eta_{r}^{*}\right|$ for silica filled PPG at $\varnothing=0.09$ (a), 0.12 (b), and 0.15 (c).

nanoparticles reinforce the nanocomposites, enhance their nonlinearity and alter the dynamic fragility of the mobile PPG phase. The reinforcement and thinning behaviours are stronger in the lower- $M_{\mathrm{w}}$ nanocomposites with the "more fragile" mobile PPG phase.

\section{Conclusion}

In silica filled PPG nanocomposites, $M_{\mathrm{W}}$ significantly influences the reinforcement without interfering the thickness of glassy layer and $T_{\mathrm{g}}$ and segmental dynamics of the mobile PPG phase. However, the mobile phase in the highly filled nanocomposite $(\varnothing$ $=0.15$ ) exhibits an abnormal "more fragile" to "stronger" transition with increasing $M_{\mathrm{w}}$. Except for $M_{\mathrm{w}}=425 \mathrm{~g} \mathrm{~mol}^{-1}$, the nanocomposites at $\varnothing \leq 0.15$ are sol-like. On the other hand, the one with $M_{\mathrm{w}}=425 \mathrm{~g} \mathrm{~mol}^{-1}$ and $\varnothing=0.15$ are gel-like and exhibits a shear-thinning behaviour being much more significant than that of the sol-like ones.

\section{Conflicts of interest}

There are no conflicts to declare.

\section{Acknowledgements}

This work was supported by the National Natural Science Foundation of China (51573157, 51790503, and 51333004), and the Key Technology Program of Guizhou Province (2013-6016).

\section{References}

1 D. F. Schmidt and E. P. Giannelis, Chem. Mater., 2010, 22, 167.

2 M. Mortezaei, M. H. N. Famili and M. Kokabi, Compos. Sci. Technol., 2011, 71, 1039.

3 Y. Yue, H. Zhang, Z. Zhang and Y. Chen, Compos. Sci. Technol., 2013, 86, 1.

4 Y. Lin, L. P. Liu, G. M. Xu, D. G. Zhang, A. G. Guan and G. Z. Wu, J. Phys. Chem. C, 2015, 119, 12956.

5 B. J. Anderson and C. F. Zukoski, Langmuir, 2010, 26, 87098720 .

6 S. Biggs, Langmuir, 1995, 11, 156.

7 C. Buenviaje, S. R. Ge, M. Rafailovich, J. Sokolov, J. M. Drake and R. M. Overney, Langmuir, 1999, 15, 6446.

8 J. Nordstrom, L. Aguilera and A. Matic, Langmuir, 2012, 28, 4080.

9 S. R. Raghavan, H. J. Walls and S. A. Khan, Langmuir, 2000, 16, 7920.

10 A. R. Studart, E. Amstad and L. J. Gauckler, Langmuir, 2007, 23, 1081.

11 K. Ueno, S. Imaizumi, K. Hata and M. Watanabe, Langmuir, 2009, 25, 825.

12 D. Fragiadakis and P. Pissis, J. Non-Cryst. Solids, 2007, 353, 4344.

13 I. Dueramae, C. Jubsilp, T. Takeichi and S. Rimdusit, Composites, Part B, 2014, 56, 197.

14 W. Zheng and S. L. Simon, J. Polym. Sci., Part B: Polym. Phys., 2008, 46, 418.

15 P. Rittigstein and J. M. Torkelson, J. Polym. Sci., Part B: Polym. Phys., 2006, 44, 2935.

16 G. Tsagaropoulos and A. Eisenberg, Macromolecules, 1995, 28, 6067.

17 C. G. Robertson and M. Rackaitis, Macromolecules, 2011, 44, 1177.

18 G. Tsagaropoulos and A. Eisenberg, Macromolecules, 1995, 28, 396.

19 J. M. Hutchinson and S. Montserrat, Thermochim. Acta, 2001, 377, 63.

20 P. Klonos, G. Dapei, I. Y. Sulym, S. Zidropoulos, D. Sternik, A. Derylo-Marczewska, M. V. Borysenko, V. M. Gun'ko, A. Kyritsis and P. Pissis, Eur. Polym. J., 2016, 74, 64.

21 P. Klonos, C. Pandis, S. Kripotou, A. Kyritsis and P. Pissis, IEEE Trans. Dielectr. Electr. Insul., 2012, 19, 1283.

22 P. Klonos, A. Panagopoulou, A. Kyritsis, L. Bokobza and P. Pissis, J. Non-Cryst. Solids, 2011, 357, 610.

23 M. Fullbrandt, P. J. Purohit and A. Schonhals, Macromolecules, 2013, 46, 4626.

24 M. Geppi, S. Borsacchi, G. Mollica and C. A. Veracini, Appl. Spectrosc. Rev., 2008, 44, 1. 
25 J. Berriot, F. Lequeux, L. Monnerie, H. Montes, D. Long and P. Sotta, J. Non-Cryst. Solids, 2002, 307-310, 719.

26 V. M. Litvinov, H. Barthel and J. Weis, Macromolecules, 2002, 35, 4356.

$27 \mathrm{~J}$. W. ten Brinke, V. M. Litvinov, J. Wijnhoven and J. W. M. Noordermeer, Macromolecules, 2002, 35, 10026.

28 A. Papon, K. Saalwachter, K. Schaler, L. Guy, F. Lequeux and H. Montes, Macromolecules, 2011, 44, 913-922.

29 T. Cosgrove, M. J. Turner and D. R. Thomas, Polymer, 1997, 38, 3885.

30 F. Saint-Michel, F. Pignon and A. Magnin, J. Colloid Interface Sci., 2003, 267, 314.

31 S. Y. Kim, H. W. Meyer, K. Saalwachter and C. F. Zukoski, Macromolecules, 2012, 45, 4225.

32 S. Cheng, A. P. Holt, H. Wang, F. Fan, V. Bocharova, H. Martin, T. Etampawala, B. T. White, T. Saito, N. G. Kang, M. D. Dadmun, J. W. Mays and A. P. Sokolov, Phys. Rev. Lett., 2016, 116, 038302.

33 M. V. Galaburda, P. Klonos, V. M. Gun'ko, V. M. Bogatyrov, M. V. Borysenko and P. Pissis, Appl. Surf. Sci., 2014, 305, 67. 34 A. P. Holt, J. R. Sangoro, Y. Y. Wang, A. L. Agapov and A. P. Sokolov, Macromolecules, 2013, 46, 4168.

35 D. Fragiadakis, P. Pissis and L. Bokobza, J. Non-Cryst. Solids, 2006, 352, 4969.

36 P. Klonos, A. Panagopoulou, L. Bokobza, A. Kyritsis, V. Peoglos and P. Pissis, Polymer, 2010, 51, 5490.

37 A. Sargsyan, A. Tonoyan, S. Davtyan and C. Schick, Eur. Polym. J., 2007, 43, 3113.

38 T. T. Ma, R. Q. Yang, Z. Zheng and Y. H. Song, J. Rheol., 2017, 61, 205.

39 Y. Song, Y. Q. Tan and Q. Zheng, Polymer, 2017, 112, 35.

40 J. P. C. Addad and L. Dujourdy, Polym. Bull., 1998, 41, 253.

41 Z. Y. Zhu, T. Thompson, S. Q. Wang, E. D. von Meerwall and

A. Halasa, Macromolecules, 2005, 38, 8816.

42 S. S. Sternstein and A. J. Zhu, Macromolecules, 2002, 35, 7262.

43 N. S. Jiang, M. K. Endoh, T. Koga, T. Masui, H. Kishimoto, M. Nagao, S. K. Satija and T. Taniguchi, ACS Macro Lett., $2015,4,838$.

44 P. Klonos, A. Kyritsis and P. Pissis, Polymer, 2015, 77, 10.

45 B. J. Anderson and C. F. Zukoski, Macromolecules, 2009, 42, 8370 .

46 V. Geiser, Y. Leterrier and J. A. E. Manson, Macromolecules, 2010, 43, 7705.

47 Z. Zheng, Y. H. Song, X. Wang and Q. Zheng, J. Rheol., 2015, 59, 971.

48 C. Gainaru and R. Bohmer, Macromolecules, 2009, 42, 7616. 49 B. A. Smith, E. T. Samulski, L. P. Yu and M. A. Winnik, Macromolecules, 1985, 18, 1901.

50 D. K. Chattopadhyay and K. V. S. N. Raju, Prog. Polym. Sci., 2007, 32, 352-418.

51 T. Lakshmipriya, Y. Horiguchi and Y. Nagasaki, Analyst, 2014, 139, 3977.

52 H. Barthel, M. Dreyer, T. Gottschalk-Gaudig, V. Litvinov and E. Nikitina, Macromol. Symp., 2015, 187, 573.

53 R. Chen, D. J. Pearce, S. Fortuna, D. L. Cheung and S. A. Bon, J. Am. Chem. Soc., 2011, 133, 2151.
54 E. Glynos, L. Papoutsakis, W. Pan, E. P. Giannelis, A. D. Nega, E. Mygiakis, G. Sakellariou and S. H. Anastasiadis, Macromolecules, 2017, 50, 4699.

55 Z. Zheng, Y. Song, H. L. Xu and Q. Zheng, Macromolecules, 2015, 48, 9015.

56 Z. Zheng, Y. Song, R. Yang and Q. Zheng, Langmuir, 2015, 31, 13478.

57 D. Kim, Y. Kim and J. Cho, Chem. Mater., 2013, 25, 3834.

58 U. T. Gonzenbach, A. R. Studart, E. Tervoort and L. J. Gauckler, Langmuir, 2006, 22, 10983.

59 F. Avilés, A. May-Pat, M. A. López-Manchado, R. Verdejo, A. Bachmatiuk and M. H. Rümmeli, Eur. Polym. J., 2018, 99, 394.

60 F. Fan, Y. Y. Wang and A. P. Sokolov, Macromolecules, 2013, 46, 9380.

$61 \mathrm{~K}$. Friedrich and S. Andreas. Broadband Dielectric Spectroscopy, Springer-Verlag Berlin Heidelberg, New York, 2003.

62 M. Tress, E. U. Mapesa, W. Kossack, W. K. Kipnusu, M. Reiche and F. Kremer, Science, 2013, 341, 1371.

63 N. Simone, G. Emmanouil and B. T. Nicholas, Rep. Prog. Phys., 2017, 80, 036602.

64 S. Srivastava, J. H. Shin and L. A. Archer, Soft Matter, 2012, 8, 4097.

65 A. P. Holt, P. J. Griffin, V. Bocharova, A. L. Agapov, A. E. Imel, M. D. Dadmun, J. R. Sangoro and A. P. Sokolov, Macromolecules, 2014, 47, 1837.

$66 \mathrm{H}$. Mortazavian, C. J. Fennell and F. D. Blum, Macromolecules, 2016, 49, 298.

67 F. J. Galindo-Rosales, F. J. Rubio-Hernandez and J. F. Velazquez-Navarro, Rheol. Acta, 2009, 48, 699.

68 L. Zhang, B. Qiu, Y. Song and Q. Zheng, RSC Adv., 2016, 6, 66336.

69 C. Gainaru, W. Hiller and R. Boehmer, Macromolecules, 2010, 43, 1907.

70 R. Richert and C. A. Angell, J. Chem. Phys., 1998, 108, 9016. 71 S. H. Zhang, P. C. Painter and J. Runt, Macromolecules, 2002, 35, 9403.

72 B. D. Fitz and J. Mijovic, Macromolecules, 1999, 32, 3518.

73 Q. Qin and G. B. McKenna, J. Non-Cryst. Solids, 2006, 352, 2977.

74 F. W. Starr and J. F. Douglas, Phys. Rev. Lett., 2011, 106, 115702.

75 R. Bohmer, K. L. Ngai, C. A. Angell and D. J. Plazek, J. Chem. Phys., 1993, 99, 4201.

76 A. L. Agapov, Y. Y. Wang, K. Kunal, C. G. Robertson and A. P. Sokolov, Macromolecules, 2012, 45, 8430.

77 W. S. Xu and K. F. Freed, Macromolecules, 2014, 47, 6990.

78 S. Askar, L. Q. Li and J. M. Torkelson, Macromolecules, 2017, 50, 1589.

79 A. Sanz, H. C. Wong, A. J. Nedoma, J. F. Douglas and J. T. Cabral, Polymer, 2015, 68, 47.

80 Y. Ding, S. Pawlus, A. P. Sokolov, J. F. Douglas, A. Karim and C. L. Soles, Macromolecules, 2009, 42, 3201.

81 H. C. Wong, A. Sanz, J. F. Douglas and J. T. Cabral, J. Mol. Liq. , 2010, 153, 79. 
82 B. A. Betancourt, J. F. Douglas and F. W. Starr, Soft Matter, 2013, 9, 241.

83 R. Mangal, Y. H. Wen, S. Choudhury and L. A. Archer, Macromolecules, 2016, 49, 5202.

84 Y. P. Koh and S. L. Simon, J. Polym. Sci., Part B: Polym. Phys., 2008, 46, 2741.

85 S. Napolitano and M. Wubbenhorst, Polymer, 2010, 51, 5309.

86 N. T. Qazvini and E. Chehrazi, J. Macromol. Sci., Part B: Phys., 2011, 50, 2165.

87 D. S. Simmons, Macromol. Chem. Phys., 2016, 217, 137.

88 K. Fukao and Y. Miyamoto, Phys. Rev. E: Stat., Nonlinear, Soft Matter Phys., 2001, 64, 011803.
89 R. A. Riggleman, K. Yoshimoto, J. F. Douglas and J. J. de Pablo, Phys. Rev. Lett., 2006, 97, 045502.

90 H. J. Yin, S. Napolitano and A. Schonhals, Macromolecules, 2012, 45, 1652.

91 P. Z. Hanakata, J. F. Douglas and F. W. Starr, J. Chem. Phys., 2012, 137, 244901.

92 M. D. Marvin, R. J. Lang and D. S. Simmons, Soft Matter, 2014, 10, 3166.

93 V. Pryamitsyn and V. Ganesan, Macromolecules, 2010, 43, 5851.

94 J. C. Majeste, J. P. Montfort, A. Allal and G. Marin, Rheol. Acta, 1998, 37, 486. 